Khazanah: Jurnal Studi Islam dan Humaniora

ISSN:0215-837X(p); 2460-7606(e),Vol. 16 (1), 2018, pp.125-142

DOI: 10.18592/khazanah.v16i1.2130

\title{
ANALISIS UNGKAPAN HONORIFIK MUTLAK DALAM MENGAKOMODASI SAPAAN DAN VERBA KEISLAMAN PADA NOVEL KARYA OKKY MADASARI
}

\section{Mochamad Nuruz Zaman, Mangatur Rudolf Nababan, Djatmika \\ Fakultas Pascasarjana, Universitas Sebelas Maret, Surakarta e-mail: Azzam.nuruzzaman93@student.uns.ac.id, amantaradja@yahoo.com,djatmika@uns.ac.id}

\begin{abstract}
This research is sociolinguistics approach of language contact of absolute honorifics in accommodating Islamic addresses and verbs on Okeky Madasari's novels. This is conducted by qualitatively descriptive by analyzing the data to be categorized the Islamic addresses and verbs in order to focus on those novels. Islamic addresses consist of nobility, general society, and Islamic verbs simultaneously able to well integrate on Okeky Madasari's novels. This development of Islamic addresses and verbs is substantially supporting theory of honorifics expressions focusing on Javenese lexicon and Indonesian language referent of respecting the utterance participants based on appropriate words.
\end{abstract}

Keywords: Absolute Honorifics, Novel, Sociolinguistics, Islamic Verb

Abstrak: Penelitian ini merupakan kajian sosilinguistik dalam menelaah kontak bahasa pada ungkapan honorifik mutlak dalam mengakomodasi sapaan dan verba keislaman pada novel karya Okky Madasari. Dikaji secara kualitatif deskriptif dengan analisis data secara domain untuk pengkategorian jenis sapaan dan verba keislaman agar terfokus pada keempat novel. Sapaan keagamaan kebangsawanan, masyarakat umum dan verba keislaman secara simultan mampu berintegrasi pada novel karya Okkey Madasari. Pengembangan teori sapaan dan verba keislaman ini merupakan substansial pendukung teori ungkapan honorifik mutlak agar mampu difokuskan pada leksikon bahasa Jawa dan kata sandang bahasa Indonesia dalam pola meninggikan pelibat tuturan sesuai pilihan kata yang tepat.

Kata kunci: Honorifik Mutlak, Novel, Sosiolingustik, Verba Keislaman 
Mochamad Nuruz Zaman, Mangatur Rudolf Nababan,

Djatmika

\section{Pendahuluan}

Kontak bahasa merupakan sebuah interaksi sosiolinguistik ketika dua atau lebih variasi bahasa digunakan secara simultan atau bercampur antara satu dengan yang lainnya. Sehingga terjadi interaksi sengaja dengan memulai pembicaraan, pemilihan bentuk sapaan, hingga respon terhadap interaksi ${ }^{1}$. Ciri pembeda ini tanpa disadari digunakan untuk mempertahankan dialek kelas sosial dan sikap dalam membangun interaksi terutama dilingkungan masyarakat penutur asli tersebut

Sejalan dengan yang dijelaskan oleh (Djatmika 2018), sebagai makhluk sosial, manusia akan selalu memerlukan interaksi dengan manusia yang lain dalam rangka memenuhi kebutuhan hidupnya masing-masing. Dengan kata lain, seseorang itu tidak akan dapat hidup dan menghidupi dirinya sendiri tanpa berhubungan dengan orang lain di dalam bingkai hidup bermasyarakat. Sementara itu, sebagian besar interaksi yang diperlukan manusia itu dilakukan dengan menggunakan bahasa. Setiap interaksi yang terjadi di masyakarat utamanya di Indonesia telah berkembang pesat dan variatif dalam pemilihan bahasa oleh pelaku interaksinya. Menurut Suwito dari sinilah timbul penegasan, bahwa bahasa merupakan bagian dari kebudayaan, dan bahasa bukan merupakan suatu yang berdiri sendiri. ${ }^{2}$ Pemakaian bahasa akan pula menimbulkan variasi kebahasaan, seperti bentuk-bentuk bagian atau variasi bahasa dalam pemakaian bahasa Jawa yang sangat tertata dengan pola umum bahasa induknya

Penelitian mengenai tuturan bahasa Jawa masih menekankan pada satu pengaruh faktor yakni perbedaan status sosial, cenderung tidak memperhatikan mengenai dengan bahasa apa ia harus bertutur ataupun kepada siapa tuturan disampaikan. Hal ini membuktikan jika belum terdapatnya variasi kebahasaan yang bertingkat - tingkat sesuai dengan tuturan yang seharusnya.

${ }^{1}$ Djatmika. "Kompetensi Wacana sebagai Kecakapan Literasi dalam Proses Pembelajaran." Seminar Nasional Pendidikan. Jombang: STKIP PGRI Jombang, 2018. 1-11.

2Suwito. Sosiolinguistik. Surakarta: Sebelas Maret University Press, 1985. 
Padahal tuturan seyogyanya harus tetap mempertahankan kaidah-kaidah dan variasi kebahasaan, namun hal tersebut kurang diperlihatkan dalam analisis tuturnya. ${ }^{3}$ Konsep tuturan yang dianalisis tidak terdapat keterkaitan situasi bagaimana tuturan disampaikan dan kemungkinan struktur apa saja yang ada dalam bahasa yang digunakan, padahal kedua konsep tersebut sangat relevan untuk membentuk sebuah kajian tingkat tutur yang sesuai. ${ }^{4}$ Banyak pula yang tumpang tindih antara dengan bahasa apa ia bertutur dan kemungkinan struktur apa saja yang ada dalam bahasa yang digunakan karena tidak terdapat deskripsi tuturan ke relevansi topik pembicaraan. Disamping itu, dalam analisisnya belum terdapat rincian gambaran tuturan yang menjadi inti permasalahan. Terdapat pula pergeseran deskripsi yang mampu berakibat pada kesalahan tingkat tuturan. ${ }^{5}$ Lebih lanjut, mereka juga belum mencantumkan mekanisme tuturan dengan deskripsi situasi dan penjelasan faktor - faktor yang mempengaruhinya. Saling tumpang tindih pemahaman ini juga diperkuat belum adanya penjelasan situasi dari masing - masing tingkat tutur. Pada akhirnya mereka juga belum meneliti bagaimana tuturan berkonstruksi ke tingkat tuturnya dengan telaah sosiolinguistik yang sesuai, yang pada akhirnya dapat pula digunakan untuk menganalisis lebih dalam mengenai tuturan terhadap representasi ungkapan honorifik.

Representasi tuturan dalam bahasa Jawa dan bahasa

${ }^{3}$ Sasangka, Sry Sasangka Tjatur Wisnu. Unggah-Unggub Bahasa Jawa. Jakarta: Yayasan Pramalingua, 2009. Lihat juga Hari, Prayogo, "Tingkat Tutur Penggunaan Bahasa Jawa Siswa SMPN 1 Wonosari: Kajian Eksistensi dan Idialek." Seminar Nasional PIBSI XXXVII. Yogyakarta: Universitas Sanata Dharma, 2015. 111-118.

${ }^{4}$ Destantri Melia Pratiwi, Analisis Wacana Keluban Bahasa Jawa: Studi Warga Desa Bangsri Kecamatan Purwantoro dan Wonogiri. Surakarta: FKIP Universitas Muhammdiyah Surakarta, 2009. Lihat juga Anjar Purwitosari, Analisis Wacana Puisi Jawa dalam Harian Solo Pos Edisi Januari - Februari 2010. Surakarta: FKIP UNiversitas Muhammadiyah Surakarta, 2010.

${ }^{5}$ Zaman, Mochamad Nuruz. "The Acceptable Indigenous and Foreign Language to the Acceptable Indonesian Language: Sosiolinguistics Case Study on UNS Print and Copy Area Overviewed within Translation Studies." International Seminar of Sociolinguistics and Dialectology. Jakarta: Universitas Indonesia, 2017. 
Mochamad Nuruz Zaman, Mangatur Rudolf Nababan, Djatmika

Indonesia sangat erat kaitannya dengan ungkapan honorifik. Menurut pandangan Kridalaksana, honorifik merupakan sistem kebahasaan yang bentuknya dipergunakan untuk ungkapan kehormatan atau penghormatan. 'Dalam beberapa bahasa, honorifik dipakai untuk menyapa orang tertentu dengan sapaan dan kata kerja, kalimat kesantunan hingga penyesuaian kalimat untuk pelibat tuturan. Pilihan bentuk - bentuk tersebut sangat menentukan kelancaraan suatu komunikasi sosial. Komunikasi akan lancar dan tetap terjaga jika antar pelibat saling menyapa dengan bentuk sapaan yang santun. Komunikasi akan berjalan searah pula apabila penutur dan mitra tutur menggunakan leksikon kesantunan yang sesuai dan saling mengerti konteks tuturan masing - masing. Hal ini sejalan dengan Brown yang mendefinisikan honorifik atau sebutan penghormatan secara lebih luas sebagai sumber daya untuk menunjuk posisi relatif mitra tutur, referen, dan orang disekitar. ${ }^{7}$ Bentuknya dapat berupa leksikon ataupun morfo-sintaksis. Lebih lanjut Levinson menjelaskan bahwa di setiap komunikasi yang dilakukan oleh partisipan tidak hanya sekedar menyampaikan pesan, tetapi lebih dari itu berkomunikasi adalah juga memelihara hubungan sosial dengan timbal balik antara penutur dan mitra tutur. ${ }^{8}$ Dengan kata lain, ungkapan honorifik pada tuturan dapat dikatakan sebagai sebagai bentuk untuk menyatakan sikap kesopanan dengan tujuan untuk menghormati lawan bicara. Sikap kesopanan dalam berbahasa tersebutlah yang mampu direalisasikan melalui ungkapan honorifik dengan bentuk kata kerja dan bentuk sapaan.

Terkait dengan ungkapan honorifik pada tuturan keagamaan, terdapat penelitian yang walaupun telah terdapat relevansi dengan topik pembicaraan, namun masih menekankan pada konstruksi kalimat, bukan pada tataran tertentu pada ungkapan honorifik keagamaan dan masih banyak menyisakan

${ }^{6}$ Kridalaksana. Kamus Linguistik (Edisi Keempat). Jakarta: PT Gramedia Pustaka Utama, 2008.

${ }^{7}$ Penelope Brown, Term of Addresses: Problems and Partners and Usage in Various Languages and Cultures . Berlin: Mounten de Gruyter, 1988.

8Penelope Brown \& Stephen Levinson, Universal in Language Usage (Questions and Politeness: Strategies in Social Interaction). Cambrigde: Cambridge University Press, 1978. 
masalah karena belum membahas spesifik mengenai sebab timbulnya ungkapan honorifik pada objek yang dianalisis dari segi konstruksi keagamaan. ${ }^{9}$ Kurangnya relevansi dengan tataran tersebut tersebut disebabkan kurang pemahaman dalam memformulasikan ungkapan yang mempresentasikan ujaran honorifik mutlak untuk membentuk pemilihan bahasa yang sesuai antar pelibat tuturan. Sehingga tuturan tersebut kurang mempertahankan ungkapan honorifik secara mutlak. Pemertahanan kaidah ungkapan honorifik mutlak pada bentuk sapaan digunakan untuk menyapa orang-orang yang sedang dalam suasana keagamaan, misalnya dimasjid atau dalam pertemuan keagamaan lainnya. dan sapaan untuk yang bekerja di dalam agama, seperti Gus, Ustadr, Ustadzah, dan sebagainya.

Ungkapan honorifik secara mutlak direpresentasikan dalam tataran keagamaan sebagai sistem yang tidak mengenal waktu (timeless). Farghal berpendapat jika ungkapan kehormatan ini mengacu pada hubungan antara pelibat tuturan (penutur atau mitra tutur atau juga objek tuturan) dan aktivitas sosial mereka. ${ }^{10}$ Yang penting di sini adalah perbedaan antara formalitas dan informalitas yang mewarnai hubungan antara peserta "peran dan situasi". Ada beberapa ungkapan tertentu yang harus pelibat tuturan sesuaikan dengan interaksi sosialnya. Kehormatan mutlak eksklusif hanya terbatas pada seseorang atau sesuatu yang diakui di masyarakat strata dan julukan sosialnya, seperti "Yang Mulia", "Profesor", “Ob God" dan lain-lain. Penerima yang berwenang tersebut adalah orang atau sesuatu yang mempunyai gelar kehormatan dengan legal dan formal, sesuai kaidah interaksi sosialnya. Selanjutnya, kehormatan sosial mutlak dapat diperluas untuk mencakup banyak fenomena yang terutama digunakan untuk tujuan sosial seperti salam, misalnya berujar Assalamu'alaikum pada forum resmi yang penduduk dominan beragama Islam.

${ }^{9}$ Suprapto. "Analisis Penerjemahan Kalimat Pasif Bahasa Inggris ke dalam Bahasa Indonesia pada Novel Morning, Noon, dam Night." Lingua Cultura Vol 7 No 1, 2013: 49-56.

${ }^{10} \mathrm{M}$. Farghal, "Kin Term and Titles of Address as Relational Social Honorifics in Jordian Arabic." Antropological Linguistics Vol 36, 1994: 250-253. 
Mochamad Nuruz Zaman, Mangatur Rudolf Nababan, Djatmika

Ujaran yang mengandung ungkapan honorifik mutlak banyak ditemukan dalam novel karya Okky Madsari yakni Entrok, Maryam, Pasung Jiwa, dan Kerumunan Terakhir. Pada novel Entrok dan Maryam banyak ditemukan sapaan dan verba yang berkaitan dengan ajaran agama Islam dengan mengaitkan kerukunan masyarakat tak mengenal agama dan masyarakat yang telah menganut kepercayaan Islam. ${ }^{11}$ Dari sinilah terkuat sapaan yang berbeda dengan verba yang berbeda pula dalam meninggikan orang untuk menhormati pelibat tuturan. Sejalan dengan itu, novel Pasung Jiwa dan Kerumunan Terakbir menegaskan perilaku untuk beretika dalam menyebarkan kebaikan, terutama dalam hal dakwah. Dakwah disampaikan melalui lisan, dan cenderung berakibat salah paham dan gagal penafsiran oleh partisipan komunikasi. Hal ini disebabkan perbedaan keyakinan (namun tetap dalam ajaran Islam) jika toleransi hanya untuk keluarga dan agama, tidak untuk bermasyarakat. Sehingga terjadi tumpang tindih sapaan dan verba untuk menunjukkan sikap arif mereka. ${ }^{12}$

Dengan kata lain, keempat novel ini berkisah tentang perjuangan seseorang dalam memahamkan agama, menggiatkan toleransi beragama, hingga konflik keagamaan yang pemilihan bahasanya perlu ditelaah lebih lanjut terkait dengan ungkapan honorifik mutlak pada sapaan dan verba yang dilakukan selama terjadi kontak bahasa dalam novel tersebut. Berdasarkan ulasan yang telah diuraikan, peneliti memiliki kesempatan untuk mengkaji lebih mendalam mengenai ungkapan honorifik mutlak dalam mengakomodasi bentuk sapaan dan verba keislaman pada novel karya Okky Madasari.

\section{Metode}

Penelitian ini merupakan kajian kualitatif dengan pendekatan deskiptif. Penelitian ini ditelaah secara Sosiolinguistik melalui objek penelitian yakni novel karya Okky

\footnotetext{
${ }^{11}$ Okky Madasari, Entrok. Jakarta: PT Gramedia Pustaka Utama, 2010. Okky Madasari Maryam,. Jakarta: PT Gramedia Pustaka Utama, 2013.

${ }^{12}$ Okky Madasari,Kerumunan Terakhir. Jakart: PT Gramedia Pustaka Utama, 2016. Okky Madasari, Pasung Jiwa. Jakarta: PT Gramedia Pustaka Utama, 2013.
} 
Madasari (Entrok, Maryam, Pasung Jiwa, dan Kerumunan Terakbir). Documentary (bibliographical study) digunakan dalam penelitian ini sebagai teknik pengumpulan data. Teknik ini dengan mengabstraksi, dari setiap dokumen, elemen yang dianggap penting dan relevan, dan dengan mengklasifikasikan penemuan atau dengan meletakkan elemen tersebut seiring dengan yang lain yang dianggap berhubungan. Documentary study yang diterapkan dalam penelitian ini mencakup analisis dokumen pada sumber data, diskusi grup terarah dengan ahli bahasa, dan wawancara mendalam terkait kevalidan data yang diteliti. Teknik analisis data secara deskriptif dalam penelitian ini menggunakan model analisis yang dikenal dengan Metodologi Etnografi. ${ }^{13}$ Model ini berasumsi bahwa setiap masyarakat memiliki sistem yang unik dalam memandang fenomena dan bahasa merupakan satu-satunya alat untuk memahami dan mengungkapkan permasalahan itu. Fokus analisis berada dalam tataran domain yakni pengkategorian yang dilakukan untuk melihat gejala keunikan pada masing-masing kategori budaya atau domain sehingga gejala tersebut dapat dipetakan. Kategori penggunaan bahasa dan konteksnya berada dalam tataran mikro yakni berupa kata - kata dalam bentuk sapaan dan verba yang diakomodasi oleh ungkapan honorifik mutlak

\section{Pembahasan}

Ungkapan honorifik (bonorifics expressions) dalam penelitian ini terfokus pada kehormatan mutlak (absolute honorifics) berdasarkan teori (Farghal 1994) Setiap kategori tersebut ditelaah dalam mengakomodasi sapaan dan verba keislaman. Sapaan dalam penelitian ini merupakan sistem yang mempertautkan seperangkat kata-kata atau ungkapan-ungkapan yang dipakai untuk menyebut dan memanggil para pelaku dalam suatu peristiwa bahasa secara konteks keislaman. Para pelaku tersebut sesuai dengan pendapat Yatim yang terdiri atas: pelibat

${ }^{13}$ Riyadi Santosa, Metode Kualitatif Kebahasaan. Surakarta: Universitas Sebelas Maret Press, 2017. 
Mochamad Nuruz Zaman, Mangatur Rudolf Nababan, Djatmika

1 (pembicara atau penutur), pelibat 2 (yang diajak bicara atau mitra tutur), dan pelibat 3 (yang dibicarakan). ${ }^{14}$

Sapaan keislaman terdiri atas sapaan keislaman kebangsawanan, masyarakat umum, dan Dzat. Sementara itu, verba keislaman terfokus pada verba asal tanpa afiks dalam konteks sintaksis.

a. Sapaan keislaman kebangsawanan

Stratifikasi masyarakat terbagi dalam dua golongan, yaitu golongan bangsawan (terpandang) dan golongan masyarakat biasa. Kedua golongan ini dalam kehidupan bermasyarakat tidak begitu terlihat perbedaannya juga dalam pemahaman tata krama pergaulan. Hanya saja yang membedakan antara kedua golongan adalah adanya gelar di depan nama yang dimiliki oleh golongan bangsawan. Sebagai contoh, sapaan "tuan guru", sapaan agung strata bangsawan kepada sesorang atas jasa dan pengabdian.

Pada data 176/MY/B6/H222 Umar pun berbisike kepada Bapak mertuanya. Bertanya itu suara siapa. "Tuan Guru Ahmad Rizki" jawab bapak Maryam. Data 176 pada novel Maryam di Bab 6 halaman 222, dengan setting di daerah Lombok, penutur memberikan jawaban atas pertanyaan Bapak mertuanya bahwa yang ber-khutbah adalah Tuan Guru Ahmad Rizki. Sapaan mitra tutur tersebut mempunyai pertimbangan utama yakni stratifikasi orang yang dimaksud adalah yang berilmu, terpandang, dan disegani di masyarakat.

"Tuan Guru" dalam bahasa sasak (Lombok) dimaknakan sebagai orang yang alim, yang memiliki pemahaman agama yang lebih dari pada manusia pada umumnya. Yang selalu menjadi panutan bagi masyarakat Lombok. Tuan guru sendiri memiliki kesamaan makna dengan "Kyal" di daerah jawa atau "Buya" bagi orang Sumatra. Jadi tuan guru bermakna yang memiliki pemahaman keilmuan agama yang disegani dan terpandang di masyarakat.

b. Sapaan keislaman masyarakat umum

${ }^{14}$ Nurdin Yatim, Subsistem Honorifik Bahasa Makassar: Sebuah Analisis Sosiolinguistik. Ujung Pandang: Departemen Pendidikan dan Kebudayaan Direktorat Pendidikan Tinggi Direktorat Pembinaan Penelitian dan Pengabdian, 1987. 
Kata sapaan keislaman dalam masyarakat merupakan katakata yang digunakan untuk menyapa orang-orang yang tidak mempunyai hubungan keluarga, namun mitra tutur mempunyai status sosial agama tinggi, dan sapaan ini lazim untuk meninggikan orang yang diajak bicara atau orang yang dibicarakan.

1) 118/EN/B5/H225 "Pak Kyai, pesantren itu isinya orangorang agama to," menunjukkan bahwa data 118 pada novel Entrok di Bab 5 halaman 225 terdapat sapaan "Pak Kyal" untuk sapaan di wilayah pesantren. Pemilihan bahasa penutur terhadap mitra tutur sesuai dengan penghormatan masyarakat umum yang dipakai seharihari di masyarakat.

2) 164/MY/B3/H121 "Pak Ustadz, tolong anak saya ini didoakan agar segera punya keturunan. Tolong dimintakan ampun kalau memang dulu pernah sesat", menunjukkan bahwa data 164 pada novel Maryam di Bab 3 halaman 121 terdapat sapaan "Pak Ustadr" untuk sapaan di wilayah desa yang masih memegang teguh tradisi keagamaan. Sapaan ini disampaikan oleh penutur kepada mitra tutur dalam konteks keagamaan. Sehingga pemilihan kata yang sesuai ditempatkan untuk sebuah penghormatan.

3) 169/MY/B5/H176 Laki-laki itu menyebut nama Abab Azir pemilik rumah yang baru saja dibakar, menunjukkan bahwa data 169 pada novel Maryam di Bab 5 halaman 176, terdapat sapaan "Abab" dinarasikan jika subyek interaksi orang yang lebih tua dan cenderung mengarah ke sapaan masyarakat umum untuk sesepuh agama. Sapaan penghormatan ini untuk meninggikan subyek kontak bahasa.

4) $177 / \mathrm{MY} / \mathrm{B} 7 / \mathrm{H} 260$ Zulkhair mengambil langkah cepat. Meminta orang-orang keluar dari rumah sakit dan menunggu di Transito. "Almarbum akan segera dibawa pulang" katanya pada orang-orang, menunjukkan bahwa data 177 pada novel Maryam di Bab 7 halaman 269, terdapat sapaan "Almarbum", penutur berinteraksi dengan masyarakat sekitar jika subyek interaksi akan segera dibawa pulang. 
Mochamad Nuruz Zaman, Mangatur Rudolf Nababan, Djatmika

Dalam konteks ini, istilah keagamaan digunakan sebagai sapaan yang tepat untuk orang yang telah meninggal dunia yakni Almarhum.

c. Sapaan keagamaan Drat

Sapaan keagamaan Dzat ini seutuhnya ditujukan kepada Dzat pemeluk dari masing-masing agama, dalam penelitian ini difokuskan pada agama Islam. Sehingga terdapat kemutlakan kehormatan yang lahir dari kepercayaan dalam memeluk agama Islam sekaligus sebagai rasa taat kepada Dzat penaung agama.

1) 001/KT/PRO/H14 "Gusti Allab, kembalikanlah Ibuku. Biarkan dia menikmati hari - hari tuanya dengan kedamaian" menunjukkan data 1 pada novel Kerumunan Terakbir prolog halaman 14, sapaan mutlak "Gusti Allab" merupakan sapaan sekaligus seruan kepada Tuhan dari pemeluk ajaran agama Islam. Dinarasikan jika subjek komunikasi meminta dan berdoa kepada-Nya agar Ibunya dikembalikan dari kesesatan ajaran agama yang Ibunya anut.

2) 160/MY/B2/H65 “Assalamualaikum, Pak..." sapa Maryam pelan menunjukkan data 160 pada novel Maryam di Bab 2 halaman 65, sapaan "Assalamu'alaikum" atau lengkapnya "Assalamu'alaikum warabmatullabhi wabarakatub" yang bermakna "Semoga keselamatan dan rahmat Allah, serta keberkahan-Nya terlimpah kepada kalian", menyapa secara langsung penutur dan mitra tutur sebagai awal mereka bertemu untuk meninggikan situasi yang hangat. Kalimat salam tidak hanya digunakan sebagai tradisi menegur sapa saja, tetapi mengandung filosofi bahwa umat Muslim harus saling mendoakan dan tidak saling membenci

3) 191/PJ/B4/H267 "Sepanjang jalan, sesekali ada yang selawatan, menyanyikan lagu-lagu yang mengagungkan Gusti Allah" menunjukkan data 191 pada novel Pasung Jiwa di Bab 4 halaman 267 yakni "Gusti Allah" juga dinarasikan secara konteks ajaran Islam melalui cerita keadaan tokoh 
komunikasi yang mengagungkannya dengan lagu seruan kepada-Nya.

Lebih lanjut, verba yang digunakan dalam penelitian ini terfokus pada verba asal sebagai bentuk kata kerja yang diakomodasi dalam ungkapan honorifik, karena data yang menunjukkan verba tidak terpengaruh oleh objek ataupun komplemen lain. Namun, cenderung asal dan stabil dalam membentuk makna dan tujuan dari kata kerja itu sendiri. Verba asal berada dalam konteks sintaksis pada tataran kalimat atau klausa. Terdapat empat kata "nyuwun" dengan makna yang berbeda-beda yang tertuang pada data berikut

a. 040/EN/B2/H56 "Nyumun supaya jadi orang pintar. Bisa jadi pegawai" kata Ibu menujukkan bahwa data 040 pada novel Entrok di Bab 2 halaman 56 verba "nyunun" menggantikan kata berdoa untuk sebuah kata kerja junjungan kepada sang pencipta. Verba ini cenderung hanya dalam konteks berdoa yang diulang setiap kali selesai beribadah. Sehingga verba ini terfokus pada pemilihan bahasa dalam konteks sholat lima waktu.

b. 032/EN/B1/H42-43 "Nduk, terserah apa penginmu. Yang penting, coba nyuwun sama Mbah Ibu Bumi Bapa Kuasa. Semua kejadian hanya terjadi kalau Dia yang menginginkan", menunjukkan bahwa data 32 pada novel Entrok di Bab 1 halaman 42-43 terdapat verba "nyumun" yang juga bermakna berdoa. Namun dalam pemilihan verba ini lebih kea rah berdoa dengan ritual keagamaan yakni dengan diiringi sholawatan dan ditempatkan di hari tertentu sebagai hari keagungan yang dipercaya mempunyai arti hari yang baik dan doa akan dikabulkan. Sehingga verba ini terfokus pada pemilihan bahasa dalam konteks hari besar pelibat tuturan percayai untuk mengamalkan doa.

c. 038/EN/B2/H55 Dia mengajariku untuk nyumun. Katanya, semua yang ada di dunia milik Mbah Ibu Bumi Bapa Kuasa., menunjukkan data 38 pada novel Entrok di bab 2 halaman 55 bahwa verba "nyumun" bermakna menengadah tangan ke atas. Cara berdoa ini diajarkan oleh Ibu ke anaknya, sebagai etika yang baik dalam berdoa. Sehingga verba ini terfokus 
Mochamad Nuruz Zaman, Mangatur Rudolf Nababan, Djatmika

pada pemilihan bahasa dalam konteks mengajarkan etika berdoa dengan cara menengadah kedua tangan ke atas

d. 084/EN/B3/H124-125 Masa aku yang sejak kecil diajari nyuwun pada Mbah Ibu Bumi Bapa kuasa tiba-tiba harus menghentikan semuanya, menunjukkan data 84 pada novel Entrok di Bab 3 halaman 124-125 bahwa verba "nyuwun" bermakna ritual kepada sang pencipta dengan cara bersemedi atau dengan cara sesuai kepercayaan masyarakat yakni memberikan sesajen. Sehingga verba ini terfokus pada pemilihan kata dalam konteks ritual dengan memberikan jamuan kepada nenek moyangnya.

Berdasarkan ulasan hasil dan pembahasan tersebut, peneliti mengakumulasi data dalam bentuk rekapitulasinya pada tabel 2 sebagai berikut.

\section{Tabel 1:}

Rekapitulasi data ungkapan honorifik mutlak dalam mengakomodasi sapaan dan verba keislaman pada novel karya Okky Madasari (Entrok, 86, Maryam, Pasung Jiwa, dan Kerumunan

\begin{tabular}{|c|c|c|c|}
\hline \multirow[b]{2}{*}{ Novel } & \multicolumn{3}{|c|}{ Terakbir) } \\
\hline & $\begin{array}{c}\text { Bentuk } \\
\text { Ungkapan } \\
\text { Honorifik } \\
\text { Mutlak }\end{array}$ & Jumlah & Persentase \\
\hline & $\begin{array}{l}\text { Sapaan } \\
\text { Keislaman }\end{array}$ & 105 & $52.5 \%$ \\
\hline & $\begin{array}{l}\text { Verba } \\
\text { Keislaman }\end{array}$ & 4 & $2 \%$ \\
\hline \multirow[t]{2}{*}{ Maryam } & $\begin{array}{l}\text { Sapaan } \\
\text { Keislaman }\end{array}$ & 54 & $27 \%$ \\
\hline & $\begin{array}{l}\text { Verba } \\
\text { Keislaman }\end{array}$ & 4 & $2 \%$ \\
\hline \multirow[t]{2}{*}{ Pasung Jiwa } & $\begin{array}{l}\text { Sapaan } \\
\text { Keislaman }\end{array}$ & 14 & $7 \%$ \\
\hline & $\begin{array}{l}\text { Verba } \\
\text { Keislaman }\end{array}$ & 0 & $0 \%$ \\
\hline $\begin{array}{l}\text { Kerumunan } \\
\text { Terakhir }\end{array}$ & $\begin{array}{l}\text { Sapaan } \\
\text { Keislaman }\end{array}$ & 19 & $9.5 \%$ \\
\hline
\end{tabular}


Analisis Ungkapan Honorifik Mutlak Dalam Mengakomodasi

Sapaan Dan Verba Keislaman Pada Novel Karya Okky Madasari

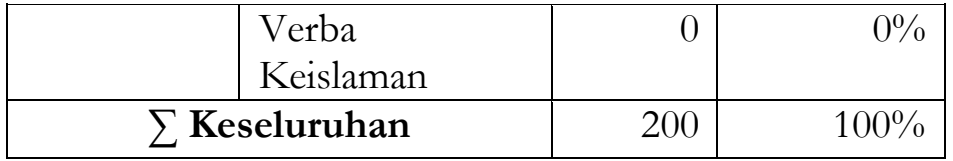

Terdapat 200 data (100\%) ungkapan honorifik mutlak pada kajian ini, dengan rincian pada novel Entrok mengakomodasi 105 data (52.5\%) sapaan keislaman dan 4 data (2\%) verba keislaman, novel Maryam mengakomodasi 54 data (27\%) sapaan keislaman dan 4 data $(2 \%)$ verba keislaman, novel Pasung Jiwa mengakomodasi 14 data (7\%) sapaan keislaman, dan novel Kerumunan Terakhir mengakomodasi 19 data (9.5\%) sapaan keislaman.

Sapaan keislaman yang terdapat dalam keempat novel tersebut menunjukkan ungkapan honorifiknya, dengan penjelasan masing-masing leksikon yang diintegrasikan dengan konsep keagamaan sebagai berikut.

a. Tuan Guru

Sapaan "Tuan Guru” ini menunjukkan makna sakral yang harus ditempatkan diatas nilai-nilai luhur dan mulia, sebagai ijazah masyarakat, karena kepercayaan dan keteladanan yang dimilikinya. Dalam pemahaman masyarakat Pulau Lombok disebut "Tuan Guru" apabila sudah menunaikan haji dan merupakan tokoh yang memiliki murid atau pengikut yang sangat banyak. Sehingga, ini memiliki arti orang yang sudah menunaikan ibadah Haji disebut juga tuan tapi tidak disebut tuan guru. Walaupun memiliki jamaah yang banyak tapi belum haji juga tidak disebut tuan guru. Walaupun menjadi guru dan haji jika tidak mengajarkan atau mendakwahkan Ilmu Agama juga tidak disebut tuan guru. Kesimpulannya ciri-ciri atau syarat disebut "Tuan Guru" adalah pernah menunaikan Ibadah Haji, memiliki ilmu pengetahuan agama Islam, mendakwahkan agama Islam, memiliki murid atau jamaah yang menyebutnya "Tuan Guru", dan taat menjalankan ajaran agama yang dibuktikan dari imaniyah, ibadah, muammalah, muasyarah dan ahlak. Hal ini sesuai dengan sapaan yang dikaitkan dengan tokoh yang bergelar "Tuan Guru" pada novel Entrok. Sehingga sapaan ini merupakan bentuk ungkapan honorific keagamaan sebagai 
Mochamad Nuruz Zaman, Mangatur Rudolf Nababan,

Djatmika

gelar kebangsawaan ajaran agama Islam masyarakat tutur Sasak.

b. Pak Kyai

Sapaan "Pak Kyai" pada novel Entrok identik dengan konsep pondok pesantren. Sapaan ini dijarkan oleh santri ataupun masyarakat sekitar untuk menunjukkan sikap hormat atas ilmu beliau. Sapaan ini dipilih atas pertimbangan sesuai dengan penokohan yang dituturkan, yakni memiliki kelebihan pengetahuan Islam, dapat menjadi perantara kerukunan, menjadi contoh yang baik, dan memiliki kedudukan layaknya orang tua. Berdasarkan pertimbangan penegasan tersebut. Sapaan ini merupakan integrasi ajaran agama Islam dengan ungkapan honorifik. Beberapa sapaan yang diujarkan dalam novel tersebut mengandung definisi keislaman jika "Pak Kyal" adalah tekun beribadah yang wajib dan sunnah, zuhud yang melepaskan diri dari ukuran dan kepentingan materi duniawi, mengerti kemaslahatan masyarakat, peka terhadap kepentingan umum dan mengabdikan seluruh ilmunya untuk Allah SWT, dan niat yang benar dalam berilmu dan beramal.

c. Abah

Sapaan "Abah" pada novel Maryam menjelaskan konsep yang tegas terhadap konsep keislaman. Dalam ujrana tersebut sapaan " $A b a b$ " diajarkan oleh penutur kepada mitra tutur dengan konsep dalam Islam, orang tua diwajibkan untuk memanggil anak-anaknya dengan sebutan yang sangat halus dan jauh dari kata kasar. Serta diajarkan salah satu sapaan yang lembut dan bisa dijadikan contoh untuk dilakukan, adalah sapaan Nabi Yusuf AS kepada sang ayah, yaitu $Y a$ Abati atau Wahai Ayahku, jika diartikan ke bahasa Indonesia dab lebih berkembang dengan sapaan "Abab". Sapaan ini cenderung untuk orang tua yang dianggap mumpuni dalam menyampaikan nasehat kepada masyarakat dan mampu memberikan petuah-petuah keagamaan baik secara kajian maupun silaturahim pendek dalam cerita ini.

d. Almarhum

Sapaan "Almarhum" pada novel Maryam untuk menghormati orang yang telah meninggal selayaknya pantas berintegrasi 
dengan ungkapan honorifik. Hal ini disebakan dalam ujaran partisipan tuturan, terdapat makna referen untuk menegaskan keberadaan toleransi antara yang masih hidup dengan yang tiada. Diantaranya adalah sapaan dipahami sebagai bentuk sebuah doa. Doa dari seorang muslim kepada saudara muslim lain yang telah meninggal. Semoga ia dirahmati Allab 'Azza wa Jalla. Serta, sapaan ini dimaksudkan untuk menjaga nama baik yang telah meninggal dan menjunjung nilai keislaman desa setempat.

e. Gusti Allah

Sapaan "Gusti Allab" di novel Kerumunan Terakbir mengindikasikan jika konteks jelas adalah lingkungan Islam. Ujaran ini menyimbolkan bentuk keagungan terhadap Allah SWT. Dalam novel ini "Gusti Allah" merupakan integrase antara budaya dan ajaran. "Gusti" bersumber dari budaya jawa yang setara dengan Pangeran atau Raja, sedangkan "Allah" adalah tuhan umat Islam. Sapaan ini dipakai untuk mengagungkan tuhan, sebab dalam cerita pelibat tuturan sedang memiliki hajat, sehingga salah satu cara dan tradisi untuk membersamai doa adalah meminta dengan sapaan "Gusti Allah".

f. Assalamu'alaikum

Sapaan "Assalamu'alaikum" di novel Pasung Jiwa ini sangat umum diketahui masyarakat tutur di dunia, utamanya pemeluk Islam. Dalam cerita di novel tersebut, sapaan ini digunakan untuk menyapa seseorang, sapaan setelah mengetuk pintu, setelah bersalam dengan orang tua, dan digunakan dalam membuka dan menutup agenda keislama dalam cerita tersebut.

Lebih lanjut, verba keislaman yang terdapat dalam keempat novel tersebut mampu berintegrasi dengan baik akan konsep keislaman yang tertuang dalam setiap makna yang berbeda. Leksikon verba keislaman "Nyuwun" memiliki empat makna yang berbeda, (1) konteks berdoa yang diulang setiap kali selesai beribadah. Sehingga verba ini terfokus pada pemilihan bahasa dalam konteks sholat lima waktu. (2) juga bermakna berdoa. Namun dalam pemilihan verba ini lebih kea rah berdoa dengan ritual keagamaan yakni dengan diiringi sholawatan dan 
Mochamad Nuruz Zaman, Mangatur Rudolf Nababan, Djatmika

ditempatkan di hari tertentu sebagai hari keagungan yang dipercaya mempunyai arti hari yang baik dan doa akan dikabulkan. Sehingga verba ini terfokus pada pemilihan bahasa dalam konteks hari besar pelibat tuturan percayai untuk mengamalkan doa. (3) bermakna menengadah tangan ke atas. Cara berdoa ini diajarkan oleh Ibu ke anaknya, sebagai etika yang baik dalam berdoa. Sehingga verba ini terfokus pada pemilihan bahasa dalam konteks mengajarkan etika berdoa dengan cara menengadah kedua tangan ke atas. Sedangkan (4) bermakna ritual kepada sang pencipta dengan cara bersemedi atau dengan cara sesuai kepercayaan masyarakat yakni memberikan sesajen. Sehingga verba ini terfokus pada pemilihan kata dalam konteks ritual dengan memberikan jamuan kepada nenek moyangnya. Perbedaan makna verba tersebut disebabkan dalam novel Entrok pelibat tuturan tidak bertuhan, sehingga masih percaya akan sesaji dan hari kebaikan.

Keempat novel ini berintegasi pada ungkapan honorifik mutlak dengan sapaan "Tuan Guru, Pak Kyai, Abah, Almarbum, Gusti Allab dan Assalamu'alaikum" dan empat verba dengan makna yang berbeda "Nyunun" menunjukkan jika pribumi di Indonesia masih mengaitkan antara budaya dan kepercayaan sebagai tradisi dan pegangan mereka dalam bekerja, beribadah, dan berinteraksi dengan sesame.

\section{Penutup}

Sapaan keagamaan kebangsawanan, masyarakat umum dan verba keislaman secara simultan mampu berintegrasi pada novel karya Okky Madasari. Pengembangan teori sapaan dan verba keislaman ini merupakan substansial pendukung teori ungkapan honorifik agar mampu difokuskan pada leksikon bahasa Jawa dan kata sandang bahasa Indonesia dalam pola meninggikan pelibat tuturan sesuai pilihan kata yang tepat. 


\section{Daftar Pustaka}

Brown, Penelope. Term of Addresses: Problems and Partners and Usage in Various Languages and Cultures . Berlin: Mounten de Gruyter, 1988.

Dajtmika. n.d.

Djatmika. "Kompetensi Wacana sebagai Kecakapan Literasi dalam Proses Pembelajaran." Seminar Nasional Pendidikan. Jombang: STKIP PGRI Jombang, 2018. 111.

Farghal, M. "Kin Term and Titles of Address as Relational Social Honorifics in Jordian Arabic." Antropological Linguistics Vol 36, 1994: 250-253.

Kridalaksana. Kamus Linguistik (Edisi Keempat). Jakarta: PT Gramedia Pustaka Utama, 2008.

Levinson, Penelope Brown \& Stephen. Universal in Language Usage (Questions and Politeness: Strategies in Social Interaction). Cambrigde: Cambridge University Press, 1978.

Madasari, Okky. Entrok. Jakarta: PT Gramedia Pustaka Utama, 2010.

- Kerumunan Terakhir. Jakart: PT Gramedia Pustaka Utama, 2016.

-. Maryam. Jakarta: PT Gramedia Pustaka Utama, 2013.

—. Pasung Jiwa. Jakarta: PT Gramedia Pustaka Utama, 2013.

Pratiwi, Destantri Melia. Analisis Wacana Keluban Bahasa Jawa:

Studi Warga Desa Bangsri Kecamatan Purwantoro dan Wonogiri. Surakarta: FKIP Universitas Muhammdiyah Surakarta, 2009.

Prayogo, Hari. "Tingkat Tutur Penggunaan Bahasa Jawa Siswa SMPN 1 Wonosari: Kajian Eksistensi dan Idialek." Seminar Nasional PIBSI XXXVII. Yogyakarta: Universitas Sanata Dharma, 2015. 111-118.

Purwitosari, Anjar. Analisis Wacana Puisi Jawa dalam Harian Solo Pos Edisi Januari - Februari 2010. Surakarta: FKIP

UNiversitas Muhammadiyah Surakarta, 2010.

Santosa, Riyadi. Metode Kualitatif Kebahasaan. Surakarta: Universitas Sebelas Maret Press, 2017. 
Mochamad Nuruz Zaman, Mangatur Rudolf Nababan,

Djatmika

Sasangka, Sry Sasangka Tjatur Wisnu. Unggah-Ungguh Bahasa Jawa. Jakarta: Yayasan Pramalingua, 2009.

Sumarsono. Sosiolinguistik. Yogyakarta: Pustaka Pelajar, 2014.

Suprapto. "Analisis Penerjemahan Kalimat Pasif Bahasa Inggris ke dalam Bahasa Indonesia pada Novel Morning, Noon, dam Night." Lingua Cultura Vol 7 No 1, 2013: 49-56.

Suwito. Sosiolinguistik. Surakarta: Sebelas Maret University Press, 1985.

Yatim, Nurdin. Subsistem Honorifik Bahasa Makassar: Sebuah Analisis Sosiolinguistik. Ujung Pandang: Departemen Pendidikan dan Kebudayaan Direktorat Pendidikan Tinggi Direktorat Pembinaan Penelitian dan Pengabdian, 1987.

Zaman, Mochamad Nuruz. "The Acceptable Indigenous and Foreign Language to the Acceptable Indonesian Language: Sosiolinguistics Case Study on UNS Print and Copy Area Overviewed within Translation Studies." International Seminar of Sociolinguistics and Dialectology. Jakarta: Universitas Indonesia, 2017. 